Original Research Article

\title{
Impact of antiepileptic drugs therapy on thyroid profile in epileptic patients of Punjab origin
}

Department of Biochemistry, Government Medical College, Patiala, Punjab, India

Received: 15 September 2019

Revised: 21 October2019

Accepted: 05 November 2019

*Correspondence to:

Dr. Kuldip Singh,

Email: drkuldip08@gmail.com

Copyright: (C) the author(s), publisher and licensee Medip Academy. This is an openaccess article distributed under the terms of the Creative Commons Attribution NonCommercial License, which permits unrestricted noncommercial use, distribution, and reproduction in any medium, provided the original work is properly cited.

\author{
Kuldip Singh*, Harleen Kaur
}

\begin{abstract}
Background: Epilepsy requires lifelong therapy with antiepileptic drugs (AEDs) and having medical and psychological consequence. So, the present study was conducted to evaluate the role of different AEDs on thyroid profile in epileptic patients.

Methods: 50 epileptic patients receiving AEDs for minimum 1 year were recruited as study group and 50 healthy subjects considered as control group. These subjects were recruited from general (rural or urban) community of Punjab. Fasting blood samples were drawn from patients and healthy subjects for the evaluation of triiodothyronine $\left(\mathrm{T}_{3}\right)$, thyroxine $\left(\mathrm{T}_{4}\right)$ and thyroid stimulating hormone (TSH) levels.

Results: Significant increase in TSH levels were recorded in epileptic patients while no significant change was found in $T_{3}$ and $T_{4}$ epileptic patients treated with different AEDs with respect to healthy controls. Maximum increase in TSH was seen in phenytoin, treated epileptic patients and maximum fall in TSH was recorded in levetiracetam treated epileptic patients. Maximum increase in $\mathrm{T}_{3}$ and $\mathrm{T}_{4}$ levels was found in phenytoin while a maximum decrease was recorded $\mathrm{T}_{3}$ and $\mathrm{T}_{4}$ levels in carbamazepine treated epileptic patients in comparison to other drugs treated patients.

Conclusions: Aforementioned observations suggested that epileptic patients treated with phenytoin, valproic acid, carbamazepine and levetiracetam for long time could cause initiation of subclinical hypothyroidism further could leads to overt hypothyroidism which in turn responsible for pathophysiology of various coronary heart disease. Routine screening of thyroid profile during chronic use of AEDs is recommended.
\end{abstract}

Keywords: Epilepsy, AEDs, $\mathrm{T}_{3}, \mathrm{~T}_{4}$, TSH

\section{INTRODUCTION}

Epilepsy is a chronic disease of the central nervous system that affects individuals of all ages and has a worldwide distribution. The disturbances of neuronal activity that occur during seizures may result in strange sensations, emotions, and behaviors. They may also sometimes cause convulsions, abnormal movements, and loss of consciousness. There are 50 million people living with epilepsy worldwide, and most of them reside in developing countries. It is estimated that there are more than 10 million persons with epilepsy in India. Its prevalence is higher in the rural (1.9\%) compared with the urban population $(0.6 \%) .{ }^{1,2}$
Patients with epilepsy are often required to take antiepileptic drugs (AEDs) for a long period of time. Many studies have shown that AEDs have a negative impact on the endocrine system including thyroid function, fertility, sexuality and bone health. ${ }^{3}$ Therapy with AEDs, remains the mainstay of treatment of patients with epilepsy. The major groupings of AEDs, can be defined as those which facilitate $\gamma$-aminobutyric acid transmission by various mechanisms; Those which block voltage-gated ion channels and thus reduce excitatory transmission; those whose mechanism of action is still open to debate. ${ }^{4}$ Most AEDs, exert their antiepileptic effects via the $\mathrm{Na}^{+}$or the $\mathrm{Ca}^{2+}$ channel or via GABAergic transmission. In chronic phase, the incidence of adverse effects with the new AEDs is low, but tocopheryl phosphate mixture and AEDs drugs that potentiate 
glutamatergic transmission, may elicit behavioral changes and cognition disorders. ${ }^{5}$ Carbamazepine and phenytoin were amongst the most prescribed AEDs, as monotherapy and as combination therapy with valproic acid while levetiracetam and lamotrigine were found frequently prescribed amongst newer AEDs.

AEDs act either by increasing inhibition through sustaining the release of g-aminobutyric acid or glycine, or decreasing excitation by inhibiting glutamate release. However, some AEDs, reduce membrane excitability by interrelating with neurotransmitter receptors or ion channels but the methods of action for most of them are not fully understood. Many studies have shown prolonged use of AEDs, is known to be associated with adverse effects such as metabolic and organ toxicity, endocrine disturbance, negative cognitive effects, and psychiatric problems.

Thyroid hormones are important for maintaining carbohydrate and lipid metabolism, cell growth and development. $^{6,7}$ Hypothyroidism even in subclinical hypothyroidism form has been associated with an increased risk of coronary heart disease. ${ }^{8}$ The prevalence of AED induced thyroid dysfunction and the long term consequences remain uncertain mainly due to routine thyroid functions tests are not performed in the clinic. Therefore, the aim of this study was to observe the impact of AEDs like phenytoin, valproic acid, carbamazepine and levetiracetam on thyroid profile in epileptic patients of Punjab origin.

\section{METHODS}

The present case control prospective study comprising total of 100 subjects was carried out in the Department of Biochemistry, Government Medical College, Amritsar, in collaboration with Department of Medicine, Guru Nanak Dev Hospital, Amritsar for the period October 2017 to July 2018. The subjects for the present study were selected from rural as well as urban community from general population of male and females. A detailed history, physical and systemic examination including measurement of height, weight, heart rate, blood pressure and body mass index (BMI) was taken and every case was thoroughly interviewed.

\section{Ethical issues}

The study protocol was approved by the institutional ethics committee. The study details and potential risks and benefits were explained to individuals taking part in the study and at least one attendant. A written informed consent was obtained from subjects before entering into the study.

\section{Inclusion criteria}

50 epileptic patients in the age range of 20-50 years of both sex (male and female) from rural or urban community of Punjab origin received one of the following AEDs (phenytoin, valproic acid, carbamazepine and levetiracetam) for a minimum period of 1 year and having five or more epileptic attacks were included in the study.

\section{Exclusion criteria}

Epileptic patients who had concomitant liver diseases, using other drugs causing elevation of liver enzymes (e.g., antibiotics, anti-rheumatic drugs, statins and nonsteroidal anti-inflammatory drugs) or those who were alcohol drinkers were excluded from the present study.

\section{Selection of normal healthy control subjects}

50 normal healthy subjects in the age range of 20-50 years of both sexes were recruited from urban or rural general population of Punjab origin.

\section{Measurement of anthropometric parameters}

The examination body weight was done by taking weight in kilogram $(\mathrm{kg})$ and height was measured in centimeters. The BMI was calculated from the formula as:

BMI=weight/height $\left(\mathrm{kg} / \mathrm{m}^{2}\right)$.

\section{Collection and processing of blood samples}

$5 \mathrm{ml}$ of venous blood was taken from all subjects after 12 hour overnight fast in a dry disposable syringe under all aseptic conditions by venepuncture in the antecubital vein in a sterile, dry acid washed vial for biochemical assays.

\section{Preparation of serum}

The blood was allowed to stand for half an hour. After clot formation, the supernatant was centrifuged. All the samples were processed for thyroid hormones, lipid profile, and liver enzymes.

\section{Biochemical assays}

Estimation of serum triiodothyronine, thyroxine and 3, 4 thyroid stimulating hormone

triiodothyronine (T3), thyroxine (T4) and 3, 4 thyroid stimulating hormone (TSH) levels in blood were analyzed by using ELISA techniques. The kits were purchased from Transasia Biomedical Private Limited, Mumbai (India). The concentrations are expressed in $\mu \mathrm{IU} / \mathrm{ml}$.

\section{Statistical analysis}

The data was expressed as mean $\pm \mathrm{SD}$ and analyzed with the SPSS 16.0.7 statistical software package. Differences between the premenopausal and post-menopausal women 
were evaluated using the Student's independent samples " $t$ " test. Differences were considered statistically significant at $\mathrm{p}<0.05$.

\section{RESULTS}

Anthropometric profile of epileptic patients and normal healthy subjects summarized in Table 1 . The age, height, body weight and BMI of epileptic patients and normal healthy subjects were ranged between $35.34 \pm 8.87$ years to $41.56 \pm 9.22$ years, $146.22 \pm 3.09 \mathrm{~cm}$ to $156.19 \pm 5.93 \mathrm{~cm}$, $46 \pm 5.21 \mathrm{~kg}$ to $56.92 \pm 4.14 \mathrm{~kg}$ and $25.76 \pm 5.32 \mathrm{~kg} / \mathrm{m}^{2}$ to $27.21 \pm 3.69 \mathrm{~kg} / \mathrm{m}^{2}$ and all were found statistically nonsignificant.

Table 1: Effect on anthropometric profile in epileptic patients on different epileptic drugs (phenytoin, valproic acid, carbamazepine, levetiracetam) and normal healthy subjects of Punjab origin.

\begin{tabular}{|lllll|}
\hline \multirow{2}{*}{ Anthropometric profile } & \multicolumn{2}{l|}{ Healthy control subjects $($ mean \pm S.D.) } & \multicolumn{2}{l|}{ Epileptic patients $($ mean \pm S.D. $)$} \\
\hline Age $($ years) & Male $(\mathbf{n = 2 8})$ & Female $(\mathbf{n}=\mathbf{2 2})$ & Male $(\mathbf{n = 3 1})$ & Female $(\mathbf{n}=\mathbf{1 9})$ \\
\hline Height $(\mathbf{c m})$ & $35.34 \pm 8.87$ & $38.22 \pm 7.52$ & $41.56 \pm 9.22$ & $40.94 \pm 8.56$ \\
\hline Body weight $(\mathbf{k g})$ & $156.19 \pm 5.93$ & $151 \pm 4.87$ & $146.22 \pm 3.09$ & $152 \pm 5.17$ \\
\hline BMI $\left(\mathbf{k g} / \mathbf{m}^{\mathbf{2}}\right)$ & $55.12 \pm 3.11$ & $46 \pm 5.21$ & $56.92 \pm 4.14$ & $48 \pm 5.25$ \\
\hline
\end{tabular}

Table 2: Effect on fasting blood glucose and blood pressure in epileptic patients on different epileptic drugs (phenytoin, valproic acid, carbamazepine, levetiracetam) and normal healthy subjects of Punjab origin.

\begin{tabular}{|c|c|c|c|c|}
\hline \multirow{2}{*}{ Biochemical assays } & \multicolumn{2}{|c|}{ Healthy control subjects (mean \pm S.D.) } & \multicolumn{2}{|c|}{ Epileptic patients (mean \pm S.D.) } \\
\hline & Male $(n=28)$ & Female $(n=22)$ & Male $(n=31)$ & Female $(n=19)$ \\
\hline Fasting blood glucose (mg/dl) & $79.67 \pm 4.76$ & $81.34 \pm 3.78$ & $81.27 \pm 5.76$ & $78.89 \pm 5.78$ \\
\hline Systolic blood pressure (mmHg) & $126.17 \pm 8.32$ & $125.22 \pm 7.89$ & $125.83 \pm 8.32$ & $126.54 \pm 5.19$ \\
\hline Diastolic blood pressure (mmHg) & $83.05 \pm 4.33$ & $81.09 \pm 4.21$ & $81.36 \pm 3.33$ & $83.22 \pm 4.72$ \\
\hline
\end{tabular}

Table 3: Effect on thyroid profile in epileptic patients on different epileptic drugs and normal healthy subjects of Punjab origin.

\begin{tabular}{|c|c|c|c|c|c|c|}
\hline \multirow{2}{*}{ Thyroid profile } & \multicolumn{3}{|c|}{$\begin{array}{l}\text { Healthy control subjects } \\
\text { (mean } \pm \text { S.D.) }\end{array}$} & \multicolumn{3}{|c|}{ Epileptic patients (mean \pm S.D.) } \\
\hline & $\begin{array}{l}\text { Male } \\
(\mathrm{n}=28)\end{array}$ & $\begin{array}{l}\text { Female } \\
(n=22)\end{array}$ & $\begin{array}{l}\text { Mean } \\
(n=50)\end{array}$ & $\begin{array}{l}\text { Male } \\
(\mathbf{n}=31)\end{array}$ & $\begin{array}{l}\text { Female } \\
(n=19)\end{array}$ & Mean $(n=50)$ \\
\hline $\begin{array}{l}T_{3}(\mathrm{ng} / \mathrm{ml}) \\
\text { [Ref. range: } 0.80-2.10]\end{array}$ & $1.11 \pm 0.35$ & $1.34 \pm 0.42$ & $1.22 \pm 0.38$ & $\begin{array}{l}1.35 \pm 0.46 \\
(21.62)\end{array}$ & $\begin{array}{l}1.26 \pm 0.37 \\
(-5.97)\end{array}$ & $\begin{array}{l}1.30 \pm 0.41 \\
(+6.97)^{\mathrm{NS}}\end{array}$ \\
\hline $\begin{array}{l}T_{4}(\mu \mathrm{g} / \mathrm{dl}) \\
\text { [Ref. range: 5.0-13.00] }\end{array}$ & $8.45 \pm 2.43$ & $7.78 \pm 1.46$ & $8.11 \pm 1.95$ & $\begin{array}{l}8.42 \pm 1.93 \\
(-0.35)\end{array}$ & $\begin{array}{l}8.02 \pm 2.21 \\
(+3.08)\end{array}$ & $\begin{array}{l}8.22 \pm 2.07 \\
(+1.35)^{\mathrm{NS}}\end{array}$ \\
\hline $\begin{array}{l}\text { TSH }(\mu \mathrm{IU} / \mathrm{ml}) \\
\text { [Ref. range: } 0.45-4.12]\end{array}$ & $2.67 \pm 0.79$ & $2.53 \pm 0.81$ & $2.60 \pm 0.80$ & $\begin{array}{l}6.11 \pm 1.72 \\
(+128.83)^{* * *}\end{array}$ & $\begin{array}{l}5.43 \pm 2.19 \\
(+114.62)^{* * *}\end{array}$ & $\begin{array}{l}5.77 \pm 1.95 \\
(+116.91)^{* * *}\end{array}$ \\
\hline
\end{tabular}

Table 4: Effect of different epileptic drugs on thyroid profile in epileptic patients of Punjab origin.

\begin{tabular}{|lllll|}
\hline Thyroid profile & Phenytoin $(\mathbf{n = 1 2})$ & $\begin{array}{l}\text { Valproic acid } \\
(\mathbf{n}=\mathbf{1 4})\end{array}$ & $\begin{array}{l}\text { Carbamazepine } \\
(\mathbf{n}=\mathbf{1 1})\end{array}$ & $\begin{array}{l}\text { Levetiracetam } \\
(\mathbf{n}=\mathbf{1 3})\end{array}$ \\
\hline $\mathbf{T}_{\mathbf{3}}(\mathbf{n g} / \mathbf{m l})$ & $1.43 \pm 0.43$ & $1.16 \pm 0.32$ & $1.14 \pm 0.43$ & $1.24 \pm 0.47$ \\
\hline $\mathbf{T}_{\mathbf{4}}(\boldsymbol{\mu} \mathbf{g} / \mathbf{d l})$ & $9.15 \pm 1.67$ & $7.92 \pm 2.05$ & $7.83 \pm 2.41$ & $8.82 \pm 1.72$ \\
\hline $\mathbf{T S H}(\boldsymbol{\mu} \mathbf{I U} / \mathbf{m l})$ & $6.62 \pm 2.81$ & $5.61 \pm 2.31$ & $5.75 \pm 1.61$ & $5.15 \pm 1.83$ \\
\hline
\end{tabular}

A maximum increase in serum TSH was recorded in phenytoin $(6.62 \pm 2.81 \mu \mathrm{IU} / \mathrm{ml})$ treated epileptic patients in comparison to valproic $(5.61 \pm 2.31 \mu \mathrm{IU} / \mathrm{ml})$, carbamazepine $(5.75 \pm 1.61 \mu \mathrm{IU} / \mathrm{mL})$, and levetiracetam $(5.15 \pm 1.83 \mu \mathrm{IU} / \mathrm{ml})$ drugs treated epileptic patients. Maximum high levels of $\mathrm{T}_{3}(1.43 \pm 0.43 \mathrm{ng} / \mathrm{ml})$ and $\mathrm{T}_{4}$ 
$(9.15 \pm 1.67 \mu \mathrm{g} / \mathrm{dl})$ was also observed in phenytoin treated epileptic patients in comparison to valproic, carbamazepine and levetiracetam drugs treated epileptic patients (Table 4).

\section{DISCUSSION}

The present case control study was conducted on 50 epileptic patients out of them 12 epileptic patients taking phenytoin; 14 patient using valproic acid; 11 epileptic patient taking carbamazepine and 13 epileptic patients on levetiracetam therapy. In present study a significant increase in TSH by $116.91 \%$ (from $2.60 \pm 0.80 \mu \mathrm{IU} / \mathrm{ml}$ to $5.77 \pm 1.95 \mu \mathrm{IU} / \mathrm{ml}$ ) levels were recorded in epileptic patients on various AEDs with respect to healthy control subjects but no significant changes were found in the levels of $\mathrm{T}_{3}$ and $\mathrm{T}_{4}$ in AEDs treated epileptic patients in comparison to healthy control subjects (Table 3 ).

A maximum increase in serum TSH was recorded in phenytoin $(6.62 \pm 2.81 \mu \mathrm{IU} / \mathrm{ml})$ treated epileptic patients in comparison to valproic $(5.61 \pm 2.31 \mu \mathrm{IU} / \mathrm{ml})$, carbamazepine $(5.75 \pm 1.61 \mu \mathrm{IU} / \mathrm{ml})$, and levetiracetam $(5.15 \pm 1.83 \mu \mathrm{IU} / \mathrm{ml})$ drugs treated epileptic patients. Maximum high levels of $\mathrm{T}_{3}(1.43 \pm 0.43 \mathrm{ng} / \mathrm{ml})$ and $\mathrm{T}_{4}$ $(9.15 \pm 1.67 \mu \mathrm{g} / \mathrm{dl})$ was also observed in phenytoin treated epileptic patients in comparison to valproic, carbamazepine and levetiracetam drugs treated epileptic patients (Table 4).

The literature reports revealed that the patients with a longer duration of epilepsy had a higher risk of high TSH. ${ }^{9,10}$ There are several mechanisms for AED induced abnormal thyroid function have been postulated, including competitive binding of thyroid hormone to thyroxine binding globulin, increased peripheral conversion of $T_{4}$ to active $T_{3}$ and interference with the hypothalamic pituitary axis. ${ }^{11-13}$ A previous prospective study also reported that alterations in thyroid function were reversible after the withdrawal of carbamazepine. ${ }^{14}$

\section{CONCLUSION}

Aforementioned observations suggested that AEDs might be responsible for the initiation of subclinical hyperthyroidism in epileptic patients if remains untreated might cause overt hyperthyroidism, a hallmark of various cardiovascular diseases (CVDs) like atherosclerosis, coronary artery disease etc. So, routine screening of thyroid profile (T3, T4 and TSH) during the chronic use of AEDs is recommended. The controlled studies with larger samples size should be carried out to reveal the further frequency and the risk factors of CVDs.

\section{ACKNOWLEDGEMENTS}

Authors are thankful to all the participants for giving us opportunity for being the part of this study.

Funding: No funding sources

Conflict of interest: None declared

Ethical approval: The study was approved by the Institutional Ethics Committee

\section{REFERENCES}

1. Moshe SL, Percucca, Ryvlin P, Tomson T. Epilepsy: new advances. Lancet. 1971;385:884-98.

2. Warren TB. Diagnosis and management of epilepsy. Cand Med Assc J. 2003;168:441-56.

3. Amudhan S, Gururaj G, Satishchandra P. Epilepsy in India I: Epidemiology and public health. Ann Indian Acad Neurol. 2015;18(3): 263-77.

4. Bafitu A. Utilisation and polypharmacy aspects of antiepileptic drugs in elderly versus younger patients with epilepsy. Epilepsy Res. 2018;139:35-42.

5. Santhosh NS, Sinha SS, Satishchandra P. Epilepsy: Indian perspective. Ann Indian Acad Neurol. 2014;17:S3-11.

6. Cansu A. Antiepileptic drugs and hormones in children. Epilepsy Res. 2010;89:89-95.

7. Tamijani SMS. Thyroid hormones: Possible roles in epilepsy pathology. Seizure. 2015;31:155-64.

8. Nadkarni J, Uikey D, Sharma U, Dwivedi R. Effect of antiepileptic drugs on lipid profile in children with epilepsy. Inter J Med Res Rev. 2014;2:119-23.

9. Zhang YX. Effect of antiepileptic drug on thyroid hormones in patients with epilepsy. Seizure. 2016;35:72-9.

10. Svalheim S, Sveberg L, Mochol M, Taubboll E. Interactions between antiepileptic drugs and hormones. Seizure 2015;46:23-7.

11. Asconape JJ. Some common issues in the use of antiepileptic drugs. Semin Neurol. 2002;22(1):27-39.

12. Arroyo S, De La Morena A. Life-threatening adverse events of antiepileptic drugs. Epilepsy Res. 2011;47:155- 74.

13. Hanaya R. The new antiepileptic dugs. Neurol Med Chir (Tokyo). 2016;56:205-20.

14. Shih FY. Effect of antiepileptic drugs on thyroid hormone functions in epilepsy patients. Seizure. 2017;48:7-10.

Cite this article as: Singh K, Kaur H. Impact of antiepileptic drugs therapy on thyroid profile in epileptic patients of Punjab origin. Int J Basic Clin Pharmacol 2019;8:2693-6. 